\title{
Intestinal bacterial contamination of surgical instruments used for wound closure during intestinal surgery
}

Follow this and additional works at: https://www.journal.acorn.org.au/jpn

Part of the Health Services Administration Commons, Health Services Research Commons, Perioperative, Operating Room and Surgical Nursing Commons, and the Surgery Commons

(c) (i)

This work is licensed under a Creative Commons Attribution 4.0 License.

\section{Recommended Citation}

Kameda, Norihiro; Nishio, Junko; Ogawa, Toshiko; and Okada, Shinobu (2018) "Intestinal bacterial contamination of surgical instruments used for wound closure during intestinal surgery," Journal of Perioperative Nursing: Vol. 31 : Iss. 3 , Article 2.

Available at: https://doi.org/10.26550/2209-1092.1034

https://www.journal.acorn.org.au/jpn/vol31/iss3/2

This Article is brought to you for free and open access by Journal of Perioperative Nursing. It has been accepted for inclusion in Journal of Perioperative Nursing by an authorized editor of Journal of Perioperative Nursing. 


\author{
Authors \\ Norihiro Kameda \\ MSN, RN \\ Faculty doctoral student, Graduate School \\ of Nursing, Chiba University. \\ Junko Nishio \\ BSCMLT \\ Laboratory Technologist, Graduate School \\ of Nursing, Chiba University. \\ Toshiko Ogawa \\ RN, PhD \\ Senior Lecturer, Graduate School of \\ Nursing, Chiba University. \\ Shinobu Okada \\ RN, PhD \\ Professor, Graduate School of Nursing, \\ Chiba University.
}

\section{Corresponding author}

Norihiro Kameda

MSN, RN

Faculty doctoral student, Graduate School of Nursing, Chiba University. norihiro0430@chiba-u.jp

\section{Intestinal bacterial contamination of surgical instruments used for wound closure during intestinal surgery}

Keywords: surgical site infections, microbiological contaminations, surgical instruments, intestinal surgeries

\section{Background}

A surgical site infection (SSI) is defined by the Centers for Disease Control and Prevention (CDC) as an infection occurring at the operative site within specific time frames, depending on the nature of the surgical procedure'. SSI incidence differs among surgeries, and intestinal surgery is one of those with a high SSI incidence. In Japan, from 2008 to 2010, SSI incidence rates for colon and rectal surgery were 15.0 and 17.8 per cent, respectively². SSI results in prolonged hospital stays and additional medical expenses ${ }^{3,4}$. (3) Therefore, SSI prevention is particularly important for improving patient outcomes.

Perioperative surgical site contamination with endogenous or exogenous bacteria is the main cause of SSI, explaining why the SSI incidence in intestinal surgery is higher than in other surgeries. Although the most common bacteria that cause SSI live on skin, such as Staphylococcus aureus and coagulase-negative staphylococci (CNS), bacteria of intestinal origin, such as Enterococcus species., Escherichia coli, Pseudomonas aeruginosa, Klebsiella pneumoniae, K. oxytoca and Acinetobacter species., have also been isolated from SSIs developed after intestinal surgeries?. Surgical incision and operating site contamination with intestinal bacteria is a particularly problematic issue during intestinal surgery.
Previous research suggests that surgical instruments transmit SSIcausing pathogens ${ }^{5}$. Thus, operating theatre staff should manage surgical instruments appropriately, distinguish contaminated instruments from clean instruments and change gloves periodically to keep the operating field as clean as possible.

Using clean instruments for wound closure is important because the subcutaneous adipose tissue is vulnerable to infection. Therefore, preparing sterilised surgical instruments specifically for wound closure is recommended to reduce SSI risk. In a prospective study in which 397 patients underwent colorectal surgeries ${ }^{6}$, the exchange of surgical instruments for dermal suturing was associated with a lower incisional SSI rate (odds ratio, 0.276). In a comparison of three types of wound closures (no irrigation, irrigation only and irrigation plus surgical instrument exchange), the SSI incidence was the lowest in the irrigation plus exchange group, followed by the irrigation and the no irrigation groups (2.1, 6.5 and 12.0 per cent, respectively; $p=0.034)$. Therefore, using sterilised instruments for wound closure is effective in reducing incisional SSIS?

In Japan, instruments not used for intestinal manipulation are considered clean, even if they were used for prior skin incisions, and they are still used for wound closure after being kept in a clean area. Koh ${ }^{8}$ 
reported that experienced nurses spent less time on the final count (count of all instrumentation, gauzes and swabs introduced into the sterile field throughout the surgery) and encountered fewer interruptions during the count than novices, indicating better task management performance. Bacteria generated from the operating field might contaminate surgical instruments in the clean area, and the surgical nurses' experience could influence this. Microbiological evaluation of these surgical instruments is necessary for the use of sterilised surgical instruments for wound closure to be accepted as a standard procedure.

In this study, we aimed to evaluate the degree and nature of contamination of surgical instruments used for wound closure during intestinal surgery and to validate the relationship between surgical features and surgical staff member's years of experience.

\section{Methods}

\section{Study facility}

We conducted this study at a teaching hospital in Japan where standard SSI-prevention measures were being practiced. This included maintaining the operating room environment at a positive pressure compared to the adjacent rooms and filtering the air through high-efficiency particulate air filters. An antimicrobial agent was administrated 60 minutes preoperatively and every three hours during surgery. Hair was clipped with surgical clippers if necessary, and the patient bathed on the day prior to surgery. Surgical instruments used for intestinal manipulation were kept separate from clean instruments and not used for wound closure. Staff exchanged surgical gloves after intestinal manipulation.

\section{Targeted surgeries}

We included only scheduled intestinal surgical procedures accompanying abdominal operations in our study. We collected samples for microbiological examination from surgical instruments used during colon surgery (COLN) and rectal surgery (REC). We also collected samples from surgical instruments used during hepatectomy (BILI-O) and pancreatic surgery (BILI-PD) as an anastomosis between the biliary duct and small intestine accompany these surgeries.

\section{Surgical staff}

We collected data concerning the gender and years of experience of the scrub nurses and surgeons participating in the targeted surgeries.

\section{Targeted instruments}

Seven instruments, including two pairs of hooked forceps, flat hooks and needle holders, and one pair of surgical scissors were examined. Table 1 displays targeted instruments and their usage. Upon commencement of surgery, a package of these instruments was opened for skin incision, kept separated from the operating field in the clean area and used only for operation in the

\section{Table 1: Target instruments and their usage}

\begin{tabular}{|l|l|}
\hline $\begin{array}{l}\text { Instrument } \\
\text { (Cooper scissors) }\end{array}$ & $\begin{array}{l}\text { Use } \\
\text { - } \text { incisiont peeling and cutting of tissue } \\
\text { intestinal tract } \\
\text { - cutting sutures }\end{array}$ \\
\hline hooked forceps & $\begin{array}{l}\text { - gripping a variety of things (instead of using } \\
\text { the fingers), such as tissue, gauze, suture } \\
\text { needle }\end{array}$ \\
\hline flat hook & $\begin{array}{l}\text { - separating muscles and tissues obstructing } \\
\text { surgeon's view }\end{array}$ \\
\hline $\begin{array}{l}\text { needle holder } \\
\text { (Matchu needle holder) }\end{array}$ & $\begin{array}{l}\text { gripping and carrying suture needle when } \\
\text { suturing organs or surgical wounds }\end{array}$ \\
\hline
\end{tabular}

clean area, if necessary (not used for surgery. We collected these surgical instruments for microbiological examination immediately prior to wound closure. Because we had collected surgical instruments that were supposed to be used for wound closure, sterile instruments prepared by the researcher were used instead for wound closure of the target surgeries.

\section{Microbiological examination}

Immediately following surgery, the seven instruments were placed into clean plastic bags and washed three times with $20 \mathrm{ml}$ of sampling solution (10.1 $\mathrm{g} \mathrm{Na}_{2} \mathrm{HPO}_{4}, 0.4 \mathrm{~g}$ $\mathrm{KH}_{2} \mathrm{PO}_{4}, 1.0 \mathrm{~g}$ Triton $\mathrm{X}-100$ made up to a final volume of $1000 \mathrm{ml}$ with distilled water). We recovered each sampling solution after washing and filtered $60 \mathrm{ml}$ through a $0.45-\mu \mathrm{m}$ membrane filter (47 $\mathrm{mm}$ diameter). The membrane filters were placed on a sterilised pad containing $2 \mathrm{ml}$ of trypticase-soy broth (Difco), cultured under microaerobic conditions for 24 hours and then under aerobic conditions for 24 hours at $37^{\circ} \mathrm{C}$. We counted the colonies growing on the filters and stained using Gram stain. All isolates from clean instruments and the predominant isolates from unclean instruments were identified intestinal manipulation), during the 
biochemically $\left(\mathrm{VITEK}{ }^{\circledR}{ }^{\circledR}\right.$ Compact; Sysmex bioMérieux) or by mass spectrometry (MALDI Biotyper $\left.{ }^{\circledR}\right)$. We compared the isolates in cases where both instruments were used for the same operation.

\section{Statistical analysis}

The Pearson $x 2$ test was used for comparing contamination among surgical procedures and risk factors among surgical procedures. Oneway analysis of variance (ANOVA) compared patient age, operation duration and the amount of bleeding during surgery. The Pearson correlation coefficient was used to analyse the relationship between the logarithmic value of the bacterial count and years of experience of the surgical staff. We used IBM SPSS ${ }^{\circledR}$ Statistics 23.0 for statistical analysis. $P<0.05$ was considered to be significant.

\section{Ethical considerations}

The study site's Ethical Review Committee approved this study as did the ethics committee of the Graduate School of Nursing, Chiba University (approval number 26-74). Data collection only proceeded after obtaining consent from patients and staff of the target surgeries. Written informed consent was sought from the surgical team (to gain access to use the surgical instruments) and from patients involved in the surgeries to allow publication of their data. Information pertaining to the patients' privacy was kept confidential.

\section{Results}

\section{Summary of the targeted surgeries and surgical staff}

Table 2 summarises instrument data collected from 31 intestinal surgeries. The surgeries included BILI-O, BILI-PD, COLN and REC cases - 10 (32.3 per cent), 10 (32.3 per cent), 6 (19.6 per cent) and 5 (16.1 per cent), respectively. A statistically significant difference in operation duration among the procedures was determined $(p=0.00)$. BILI-PD surgeries were the longest operations and COLN were the shortest.

\section{Surgical instrument contamination}

We obtained samples from 217 surgical instruments and isolated bacteria from 190 (87.6 per cent) instruments. The amount of detected bacteria ranged from 2.0 to $1.7 \times 10^{4}$ CFU (colony forming units).

The degree of contamination of each instrument was categorised according to the logarithmic value of detected numbers of bacteria as follows:

1. no detection (-), not contaminated

2. $\log 10 \mathrm{CFU}<1.5( \pm)$, slightly contaminated

3. $1.5 \geq \log 10$ CFU $<2.5(+)$, mildly contaminated

4. $2.5 \geq \log 10$ CFU $<3.5(++)$, moderately contaminated

5. $\log 10 \mathrm{CFU} \geq 3.5(+++)$, severely contaminated.

Table 2: Summary of the targeted operations

\begin{tabular}{|c|c|c|c|c|c|c|c|}
\hline & & & \multicolumn{4}{|c|}{ Surgical procedure } & \multirow[t]{2}{*}{$P^{*}$} \\
\hline & & $(N=31)$ & BILI-O & BILI-PD & COLN & REC & \\
\hline \multirow[t]{2}{*}{ Gender (n) } & Male & $21(67.7 \%)$ & $6(19.4 \%)$ & $2(22.6 \%)$ & $3(9.7 \%)$ & $5(16.1 \%)$ & \multirow[t]{2}{*}{0.32} \\
\hline & Female & $10(32.3 \%)$ & $4(12.9 \%)$ & $3(9.7 \%)$ & $3(9.7 \%)$ & - & \\
\hline Age $($ Mean $\pm S D)$ & & $65 \pm 15.2$ & $62.4 \pm 14.9$ & $67.1 \pm 8.4$ & $60.7 \pm 19.9$ & $64.2 \pm 15.0$ & 0.45 \\
\hline $\begin{array}{l}\text { Wound classification } \\
\text { (n) }\end{array}$ & Class II & $31(100 \%)$ & & & & & \\
\hline \multirow[t]{3}{*}{ ASA-PS (n) } & 1 & $5(16.1 \%)$ & $2(6.5 \%)$ & $2(6.5 \%)$ & - & $1(3.2 \%)$ & \multirow[t]{3}{*}{0.28} \\
\hline & 2 & $23(74.2 \%)$ & $8(25.8 \%)$ & $8(25.8 \%)$ & $4(12.9 \%)$ & $3(9.7 \%)$ & \\
\hline & 3 & $3(9.7 \%)$ & - & - & $2(6.5 \%)$ & $1(3.2 \%)$ & \\
\hline \multirow[t]{3}{*}{ Risk index (n) } & 0 & $2(6.5 \%)$ & - & - & $2(6.5 \%)$ & - & \multirow[t]{3}{*}{0.00} \\
\hline & 1 & $27(87.1 \%)$ & $10(32.3 \%)$ & $10(32.3 \%)$ & $2(6.5 \%)$ & $5(16.1 \%)$ & \\
\hline & 2 & $2(6.5 \%)$ & - & - & $2(6.5 \%)$ & - & \\
\hline $\begin{array}{l}\text { Operation length in } \\
\text { minutes (Mean } \pm S D \text { ) }\end{array}$ & & $374.6 \pm 114.3$ & $405.5 \pm 24.1$ & $456.7 \pm 18.5$ & $226.0 \pm 31.9$ & $327.0 \pm 53.7$ & 0.00 \\
\hline Bleeding (ml) & & $882.9 \pm 793.7$ & $1239.0 \pm 363.7$ & $523.3 \pm 289.0$ & $523.3 \pm 289.0$ & $840.0 \pm 108.7$ & 0.34 \\
\hline
\end{tabular}

${ }^{\star} \mathrm{P}<0.05$ was considered to be significant. 
Table 3: Instrument contamination level and comparison of instrument contamination by surgical procedure

\begin{tabular}{|c|c|c|c|c|c|c|c|}
\hline \multirow[b]{2}{*}{ Type of surgery } & \multirow[b]{2}{*}{ Instrument } & \multirow[b]{2}{*}{$\mathrm{n}$} & \multicolumn{5}{|c|}{ Degree of contamination* } \\
\hline & & & - & \pm & + & ++ & +++ \\
\hline \multirow[t]{5}{*}{ BILI-O } & surgical scissors & 10 & 0 & 2 & 6 & 1 & 1 \\
\hline & hooked forceps & 20 & 0 & 12 & 6 & 2 & 0 \\
\hline & flat hook & 20 & 3 & 6 & 10 & 0 & 1 \\
\hline & needle holder & 20 & 1 & 10 & 6 & 1 & 2 \\
\hline & BILI-O total & 70 & $4(5.7 \%)$ & $30(42.9 \%)$ & $28(40.0 \%)$ & $4(5.7 \%)$ & $4(5.7 \%)$ \\
\hline \multirow[t]{5}{*}{ BILI-PD } & surgical scissors & 10 & 2 & 2 & 4 & 2 & 0 \\
\hline & hooked forceps & 20 & 4 & 8 & 5 & 3 & 0 \\
\hline & flat hook & 20 & 5 & 9 & 6 & 0 & 0 \\
\hline & needle holder & 20 & 3 & 16 & 1 & 0 & 0 \\
\hline & BILI-PD total & 70 & $14(20.0 \%)$ & 35 (50.0\%) & $16(22.9 \%)$ & $5(7.1 \%)$ & $0(0.0 \%)$ \\
\hline \multirow[t]{5}{*}{ COLN } & surgical scissors & 6 & 1 & 0 & 3 & 1 & 1 \\
\hline & hooked forceps & 12 & 2 & 7 & 3 & 0 & 0 \\
\hline & flat hook & 12 & 3 & 5 & 3 & 1 & 0 \\
\hline & needle holder & 12 & 3 & 4 & 3 & 2 & 0 \\
\hline & COLN total & 42 & $9(21.4 \%)$ & 16 (38.1\%) & $12(28.6 \%)$ & $4(9.5 \%)$ & $1(2.3 \%)$ \\
\hline \multirow[t]{6}{*}{ REC } & surgical scissors & 5 & 0 & 0 & 3 & 1 & 1 \\
\hline & hooked forceps & 10 & 0 & 7 & 1 & 2 & 0 \\
\hline & flat hook & 10 & 0 & 4 & 5 & 1 & 0 \\
\hline & needle holder & 10 & 0 & 6 & 4 & 0 & 0 \\
\hline & REC total & 35 & $0(0.0 \%)$ & $17(48.6 \%)$ & $13(37.1 \%)$ & $4(11.4 \%)$ & $1(2.8 \%)$ \\
\hline & Total instruments & 217 & $27(12.4 \%)$ & $98(45.2 \%)$ & $69(31.8 \%)$ & $17(7.8 \%)$ & $6(2.8 \%)$ \\
\hline
\end{tabular}

* Degree of contamination:

- (no contamination)

Table 3 shows the degree of contamination of each instrument in the four types of surgical procedures investigated. We observed contamination in more than two of the seven instruments in all surgeries, and contamination of all instruments was observed in 18 (58.1 per cent) cases. The chance of instrument contamination in BILI-O and REC was 94.2 and 100 per cent, respectively, and this chance was significantly greater than that observed in BILI-PD and COLN (80.0 and 78.5 per cent, respectively; $p=0.004)$. The ratio of severely contaminated $(+++)$ instruments \pm (slightly contaminated)

+ (mildly contaminated)

was the greatest in BILI-O (5.7 per cent). In COLN and REC, 9.5 and 11.4 per cent of instruments, respectively, were moderately contaminated $(++)$. Severely and moderately contaminated instruments accounted for 11.4, 11.9 and 14.3 per cent of instruments in BILI-O, COLN and REC, respectively, but they accounted for only 7.1 per cent of instruments in BILI-PD. There was no bacterial isolation in 20.0 and 21.4 per cent of instruments used in BILI-PD and COLN, respectively. Conversely, we did not isolate any bacteria in 5.7 per cent of instruments used in BILI-O
++ (moderately contaminated)

+++ (severely contaminated).

and 0.0 per cent of instruments used in REC.

\section{Detected bacterial species}

We isolated 627 bacteria from the surgical instruments. The most frequently isolated species were Staphylococcus species (206 isolates, 32.9 per cent), including Staphylococcus aureus (17 isolates, 2.7 per cent) and CNS (189 isolates, 30.1 per cent). Bacillus species (159 isolates, 25.4 per cent) and Enterococcus species (47 isolates, 7.5 per cent) were also frequently isolated. Gram negative rods, such as Escherichia coli, Pseudomonas 
Table 4: Bacterial species of 627 isolates derived from surgical instruments

\begin{tabular}{|l|c|}
\hline Bacteria & Number of isolates \\
\hline coagulase-negative staphylococci (CNS) & $189(30.1 \%)$ \\
\hline Staphylococcus aureus & $17(2.7 \%)$ \\
\hline Bacillus species & $159(25.4 \%)$ \\
\hline Enterococcus species & $47(7.5 \%)$ \\
\hline Escherichia coli & $12(1.9 \%)$ \\
\hline Pseudomonas aeruginosa & $13(2.1 \%)$ \\
\hline Klebsiella pneumoniae & $14(2.2 \%)$ \\
\hline Klebsiella oxytoca & $2(0.3 \%)$ \\
\hline Acinetobacter baumannii & $2(0.3 \%)$ \\
\hline Other bacteria & $172(27.4 \%)$ \\
\hline Total & $627(100 \%)$ \\
\hline
\end{tabular}

aeruginosa, Klebsiella pneumoniae, $K$. oxytoca and Acinetobacter baumannii were also detected at 12 (1.9 per cent), 13 (2.1 per cent), 14 (2.2 per cent), 2 (0.3 per cent) and 2 (0.3 per cent) isolates, respectively (see Table 4).
Most of the isolated bacteria were organisms that cause SSI. Figure 1 presents detection of SSI causative bacteria during each surgical procedure. CNS was detected in almost all cases. It was detected in nine cases (90.3 per cent) of BILI-O and BILI-PD, five cases (83.3 per cent) of COLN and five cases (100 per cent) of REC. Enterococcus species were the second most frequently isolated bacteria. They were found in four cases (40.0 per cent) of BILI-O and BILI-PD, three cases (50.0 per cent) of COLN and one case (20.0 per cent) of REC. S. aureus was detected in six cases - two cases (20.0 per cent) of BILI-O and BILI-PD, one case (17 per cent) of COLN and one case of REC. E. coli was also detected in six cases four cases (50.0 per cent) of BILI-O, one case (16.7 per cent) of COLN and one case (20.0 per cent) of REC. E cloacae was detected in five cases two cases (20.0 per cent) of BILI-PD, two cases of COLN (33.3 per cent) and one case of REC (20.0 per cent) - and $P$. aeruginosa was isolated in one case of BILI-O.

The bacteria detected were divided into two groups according to their

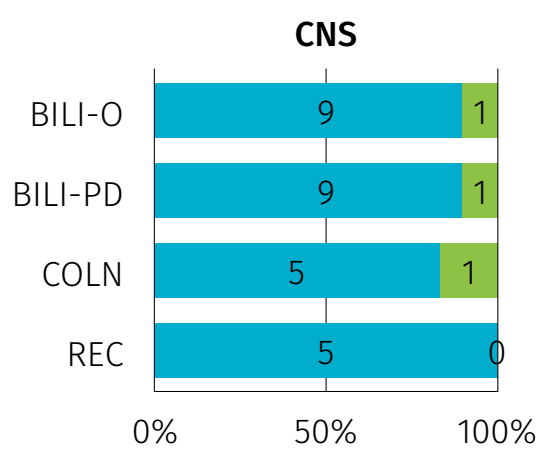

E. Coli

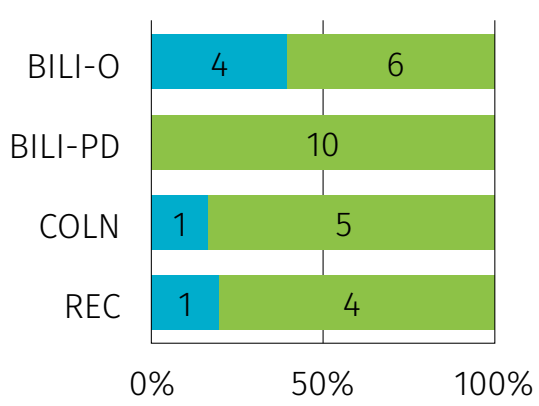

\section{S. aureus}

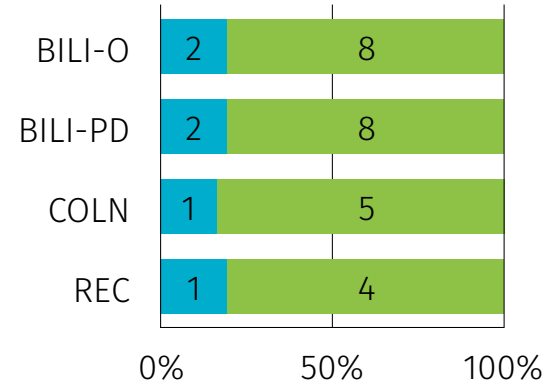

E. cloacae

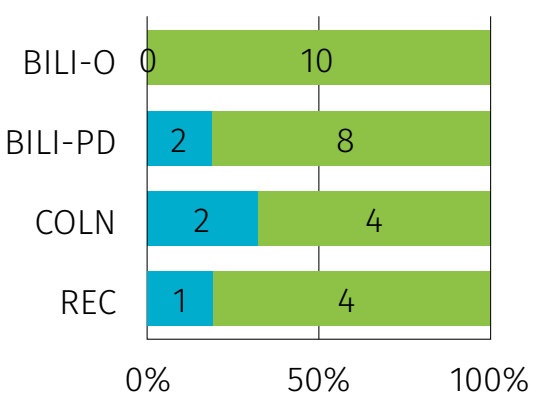

\section{Enterococcus spp.}

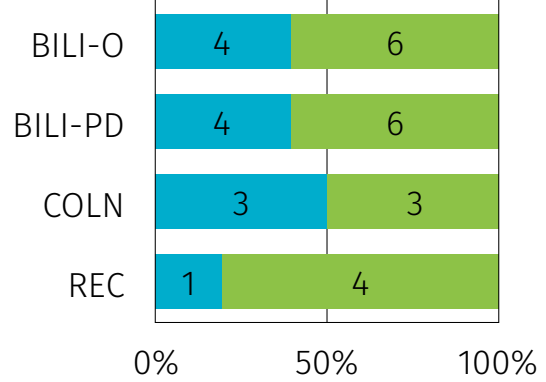

Figure 1: SSI causative bacteria and the number of cases in which they were detected on any of the seven clean instruments used in the four types of surgery (Blue indicates bacteria detected, green indicates bacteria not detected.) 
habitats - skin-derived bacteria were CNS, S. aureus and other Gram positive cocci while intestine-derived bacteria were Enterococcus species, E. coli, P. aeruginosa, Lactobacillus species, Bacillus species and other Gram positive and Gram negative rods. In this study, depending on the characteristics of the environment to which the surgical instruments were exposed and the detected bacterial load, Bacillus species and other Gram positive rods were considered to be derived from the patient's intestine even if they were also isolated from the environment.

An analysis of the total bacterial load on the seven targeted instruments in 31 surgeries showed that the amount of intestine-derived bacteria exceeded the number of skinderived bacteria in 18 (58.1 per cent) of the 31 cases. The cases with the highest cumulative loads in all seven instruments were a BILI-O case (No. 24) with $3.5 \times 10^{4}$ CFU intestinederived bacteria and an REC case (No. 31) with $8.1 \times 10^{2}$ CFU skin-derived bacteria.

\section{Relationship between years of experience and instrument contamination}

The mean number of years experience of the surgical staff performing the 31 targeted surgeries were $4.8 \pm 4.3$ years for scrub nurses and $25.6 \pm 10.8$ years for surgeons. Thirteen female and seven male scrub nurses and 15 male surgeons were involved in the targeted surgeries. Of these, eight scrub nurses and six surgeons participated in two or more surgeries. A comparison of cases of the same surgical type in which the same nurse participated showed that bacterial amounts varied. For example, nurse $O$ participated in three BILI-PD cases and the log values of the bacteria detected were 3.5, 2.4 and 0.7.
The relationship between the years of experience of surgical staff participating in each surgery and the total amount of bacteria of the seven targeted instruments expressed as logarithmic values was analysed. The correlation coefficients between the years of experience of the scrub nurses and surgeons and the number of bacteria were 0.1 and 0.14, respectively, and no significant correlation was detected ( $p=0.59$ and $p=0.44$, respectively). Even for intestine-derived bacteria alone, correlation coefficients between the years of experience of the surgical staff and the number of bacteria were 0.07 and 0.19 , respectively, and no significant correlation was found ( $p=0.71$ and $p=0.30$, respectively).

\section{Discussion}

Bacterial contamination of the surgical site necessarily precedes sSI development ${ }^{1}$. Therefore, using contaminated surgical instruments for wound closure contaminates the surgical site, increasing the SSI risk.

In this study, we examined surgical instruments that were supposed to be used for wound closure in intestinal operations. We observed bacterial contamination in 87.6 per cent of instruments. The isolated bacteria included Enterococcus species, E. coli, P. aeruginosa, $K$. pneumoniae, K. oxytoca, A. baumannii and Bacillus species, apparently derived from intestinal tracts. We isolated Enterococcus species and E.coli in 38.7 and 19.4 per cent of cases, respectively. These bacteria have also been frequently identified as causes of SSI by surveillance of National Healthcare Safety Network, from 2006 to $2007^{9}$. Of particular interest, we detected $P$. aeruginosa in one case of upper intestinal surgery (BILI-O). It was reported that $P$. aeruginosa was found in gastrointestinal flora and its detection rate increases with an increased length of hospital stay. Results from our study suggest that these SSI causative bacteria might contaminate the surgical wound when instruments for wound closure become contaminated with these bacteria.

We divided the isolated bacteria into skin-derived and intestine-derived bacteria. The amount of intestinederived bacteria outweighed skinderived bacteria in 58.1 per cent of cases and surgical instruments were more heavily contaminated with intestine-derived bacteria than skinderived. During intestinal surgery in Japan, surgical instruments that are in direct contact with the intestinal tract are isolated from other clean instruments to prevent droplet and contact transmission of intestinal bacteria to the clean instruments reused for wound closure ${ }^{10}$. The results of our study suggest that bacteria in operating fields are transmitted to other surgical instruments during the surgery even if they are separated from operating fields as clean instruments and are not used for intestinal manipulation.

Intestinal bacteria could be transmitted by droplets splashed from the operating field or through contact by operating room personnel. It has been reported that droplet splash of invisible droplets could occur during surgery. A study investigating the exposure of face-shield masks to blood during surgery revealed traces of blood on 151 of 330 face-shield masks, unnoticed by 97.2 per cent of participants ${ }^{11}$. Similarly, invisible droplets generated from the opened intestinal lumen may contaminate clean instruments. These droplets probably contain a large amount of intestinal bacteria, thereby resulting in severe contamination of surgical instruments. 
In addition to droplet transmission, direct contact transmission by operating room personnel might occur. In a study of 941 patients undergoing surgeries because of upper and lower digestive tract diseases, the frequency of glove changes was reported as an independent factor to reduce SSI risk $^{12}$. This study supports our opinion that bacterial transmission by direct contact occurs during surgery. As with droplet transmission, the incidence of contact transmission increases with an increase in bacterial load in the operating field.

This possibility is supported by our finding that the ratio of severely and moderately contaminated instruments used in COLN and REC surgeries with relatively shorter duration were similar to that of severely and moderately contaminated instruments used in BILI-PD. Generally, lower gastrointestinal tract surgeries have a heavier bacterial load than upper gastrointestinal tract surgeries ${ }^{13}$. Thus, in surgeries involving organs where the bacterial load is generally heavy, bacteria are more likely to disperse into the surrounding environment. Heavier contamination of the instruments contaminated with intestine-derived bacteria rather than skin-derived bacteria also suggests that droplet or contact transmission from intestinal tracts might cause severe contamination.

Contamination of surgical instruments with skin-derived bacteria, including Staphylococcus species, was expected because the targeted instruments might have been used for skin incision before sampling. S. aureus and CNS were detected in 19.4 and 90.3 per cent of cases, respectively. Although the degree of contamination by skin-derived bacteria was lower than contamination by intestinederived bacteria in 18 cases, the surgical instruments in some cases were highly contaminated with skin-derived bacteria. As reported previously, S. aureus and CNS can cause SSI by contaminating skin incision sites ${ }^{14,15}$. Thus, the reduction of contamination with skin-derived bacteria must also be considered.

We predicted that instruments in surgeries where less experienced scrub nurses were involved would be more contaminated because of inappropriate handling of surgical instruments due to a lack of experience, which increases the chance of bacterial spread. However, there was no correlation between the years of experience of the scrub nurses and the number of colonies detected. Rather, our results suggest that surgical instrument contamination is determined by the type of surgery, and contamination cannot be completely avoided when opening the intestine is part of the surgical procedure.

Bacterial contamination of surgical instruments during surgical procedures has already been observed in a previous investigation ${ }^{5}$. The positive culture rate in our study (87.6 per cent) was three times higher than that reported in a previous study (31.4 per cent). Isolated bacteria were almost similar to those observed in our study, although more Gram positive and Gram negative rods were isolated in our study. In the previous study, samples were collected from two pairs of forceps only, and gastrectomy and abdominal aortic aneurysm repair were included. Thus, differences in targeted instruments and surgeries and culture conditions might be a possible explanation for the higher positive culture rate of Gram positive and Gram negative rods in our study.

Previous studies did not consider what the targeted surgical instruments were used for and where they were kept during the surgery ${ }^{5,16}$. Our study focussed on the surgical instruments to be used for wound closure. The fact that they were heavily contaminated indicates the risk of contamination of surgical wounds by surgical instruments. We have provided direct bacteriological evidence to support the necessity of using sterilised surgical instruments for wound closure.

\section{Conclusion}

This study examined microbiological contaminations of the surgical instruments used in 31 intestinal surgeries accompanying manipulation of the gastrointestinal tract. We revealed that instruments used for wound closure were contaminated not only with skin-derived bacteria but also with intestine-derived bacteria. Some instruments were heavily contaminated, and their use for wound closure might cause incisional SSI. The degree of contamination was not affected by the years of experience of the scrub nurses and surgeons involved in the surgery. Our results indicate that a new set of sterilised surgical instruments should be prepared for wound closure to minimise SSI risk.

\section{References}

1. Mangram AJ, Horan TC, Pearson ML, Silver LC, Jarvis WR. Guideline for prevention of surgical site infection, 1999. Centers for Disease Control and Prevention (CDC) Hospital Infection Control Practices Advisory Committee, Infect Control Hosp Epidemiol 1999;20(4):250-278; quiz 279-280.

2. Morikane K, Honda H, Yamagishi T, Suzuki $S$, Aminaka M. Factors associated with surgical site infection in colorectal surgery: The Japan nosocomial infections surveillance. Infect Control Hosp Epidemiol 2014;35(6):660-666.

3. Glickman SW, Ou FS, DeLong ER, Roe MT, Lytle BL, Mulgund J et al. Pay for performance, quality of care, and outcomes in acute myocardial infarction. JAMA 2007;297(21):2373-2380. 
4. Stone PW, Braccia D, Larson E. Systematic review of economic analyses of health careassociated infections. Am J Infect Control 2005;33(9):501-509.

5. Saito $Y$, Kobayashi H, Uetera $Y$, Yasuhara $H$, Kajiura T, Okubo T. Microbial contamination of surgical instruments used for laparotomy. Am J Infect Control 2014;42(1):43-47.

6. Takahashi K, Funayama Y, Ikezawa $\mathrm{F}$, Tokumura $\mathrm{H}$, Toshima T, Musha $\mathrm{H}$ et al. Evaluation of risk factors which are associated with incisional surgical site infection and adequate precautions in colorectal surgery. Journal of Japan Society for Surgical Infection 2012;9(6):641-647.

7. Tanida T, Yamada T, Tanaka K, Tomimaru Y, Kishi K, Noura S et al. Trial of ICT intervention for the prevention of wound infection after colorectal surgery. Journal of Japan Society for Surgical Infection 2007;4(4):499-502.

8. Koh RY, Park T, Wickens CD, Ong LT, Chia $\mathrm{SN}$. Differences in attentional strategies by novice and experienced operating theatre scrub nurses. J Exp Psychol Appl 2011;17(3):233-246.
9. Hidron Al, Edwards JR, Patel J, Horan TC, Sievert DM, Pollock DA et al. NHSN annual update: Antimicrobial-resistant pathogens associated with healthcare-associated infections: Annual summary of data reported to the National Healthcare Safety Network at the Centers for Disease Control and Prevention, 2006-2007. Infect Control Hosp Epidemiol 2008;29(11):996-1011.

10. Harihara Y. Prevention of surgical site infection (Clinical practice guideline for operative medicine, revised edition). Journal of Japanese Association for Operative Medicine (2013);34:S58-S70.

11. Nakamura E, Imazeki A, Torikoe M, Suzuki $K$, Mizutani M, Ohtsuka M. Investigation of the frequency of exposure of blood and fluid of patients to a scrub nurse during operation: Usefulness of a face-shield mask. Journal of Japanese Association for Operating Room Technology 2006;27(2):93-98.

12. Watanabe A, Kohnoe S, Shimabukuro R, Yamanaka T, Iso Y, Baba H et al. Risk factors associated with surgical site infection in upper and lower gastrointestinal surgery Surg Today 2008;38(5):404-412.
13. Hirayama Kazuhiro. Introduction to intestinal microbiota. Modern Media 2008;60(10):307-311.

14. Kalra L, Camacho F, Whitener CJ, Du P, Miller $M$, Zalonis C et al. Risk of methicillinresistant Staphylococcus aureus surgical site infection in patients with nasal MRSA colonization. Am J Infect Control 2013;41(12):1253-1257.

15. Levy PY, Ollivier M, Drancourt M, Raoult $D$, Argenson JN. Relation between nasal carriage of Staphylococcus aureus and surgical site infection in orthopedic surgery: The role of nasal contamination. A systematic literature review and metaanalysis. Orthop Traumatol Surg Res 2013;9(6):645-651.

16. Rutala WA, Gergen MF, Weber DJ. Microbial contamination on used surgical instruments. Infect Control Hosp Edipemiol 2014;35(8):1068-1070. 